\title{
COMPARISON OF FUZZY LOGIC AND NEURAL NETWORK For MODELLING SURFACE ROUGHNESS IN EDM
}

\author{
Dragan Rodic ${ }^{1}$, Marin Gostimirovic ${ }^{1}$, Pavel Kovac ${ }^{1}$, Miroslav Radovanovic ${ }^{2}$ and \\ Borislav Savkovic ${ }^{1}$ \\ ${ }^{1}$ University of Novi Sad, Faculty of Technical Sciences, Institute for Production \\ Engineering, Trg Dositeja Obradovica 6, 21000 Novi Sad, Serbia \\ ${ }^{2}$ University of Niš, Faculty of Mechanical Engineering, Laboratory for Machine Tools \\ and Machining, Aleksandra Medvedeva 14, 18000 Niš Serbia
}

\begin{abstract}
Surface roughness is the main indicator of technological performances of a component for electrical discharge machining (EDM). EDM process of manganese alloyed cold-work tool steel was modelled. In this paper we used the fuzzy logic $(F L)$ and neural network $(N N)$ to predict the effect of machining variables (discharge current and pulse duration) on the surface roughness of manganese alloyed cold-work tool steel in order to improve and increase its range of application. The experiments are carried out on manganese alloyed cold-work tool steel, processed with electrodes made of copper. The values of surface roughness predicted by these models are then compared. All models show good agreement with experimental results. When compared to the NN and FL models, the NN model has shown a significant forecast improvement. The results indicate that the NN model is an effective algorithm to forecast the surface roughness in EDM.
\end{abstract}

\section{KEYWORDS}

EDM, surface roughness, fuzzy logic, neural network

\section{INTRODUCTION}

Now-a-days, due to the increasing demand of higher efficiency and quality, surface roughness of a machined part plays an important role in the modern manufacturing process. The quality of finished products is defined by how closely the finished product adheres to certain specifications, including dimensions and surface quality. Surface quality is defined and identified by the combination of surface finish, surface texture, and surface roughness. Surface roughness $\left(R_{a}\right)$ is the commonest index for determining surface quality $[1,2]$.

EDM is non-traditional machining processes in modern machining to economically machine materials that are usually difficult to machine with the conventional tools. This machining is one of the most widely applied process for machining and shaping difficult to cut materials, which with an electrode transforms electrical energy into thermal energy for removing materials. The top surface of the workpiece resolidifies and subsequently cools extremely quickly to form a hard skin on the workpiece [3]. This layer causes an increase in surface roughness and makes the surface hard and brittle [4]. To know the surface quality, it is necessary to employ theoretical models making it feasible to do predictions in function of response parameters [5]. EDM process of manganese alloyed cold-work tool steel was modelled in this paper using the fuzzy logic (FL) 
and neural network (NN) to predict the effect of machining variables (discharge current and pulse duration) on the surface roughness of manganese alloyed cold-work tool steel in order to improve and increase its range of application.

Recently, some initial investigations in applying the basic fuzzy logic and neural network approaches to model machining processes. To generalize the experimental results and develop the system model accurately, neural networks and fuzzy systems are reported as an alternative approach [6,7]. Yilmaz et al. [8] presented an intelligent system for the selection of electro discharge machining parameters which lead to less electrode wear, better surface quality and more erosion rate according to the selected operation (finishing, roughing, etc.). Rao et al. [9] developed mathematical model for predicting die-sinking electrical discharge machining of aluminium alloy characteristics such as the metal removal rate, the tool wear rate, the surface roughness ( $R_{a}$ value) and the hardness using fuzzy mathematical method. Lin et al. [10] presented the use of fuzzy logic to the Taguchi method for the modeling and optimization of the EDM process with the multiple performance characteristics. Shabgard et al. developed a fuzzy-based algorithm for prediction of material removal rate, tool wear ratio, and surface roughness in the EDM and ultrasonic-assisted EDM processes. In this system, discharge current, pulse duration, and ultrasonic vibration of tool are the input variables and outputs are material removal rate, too wear ratio and surface roughness [11]. Tsai et al. [12] presented neural network models in order to predict the surface finish of work and material removal rate in EDM process. It was noted that the model produces a more reliable surface finish prediction for a given work under different process conditions. Spedding and Wang [13] applied the RSM along with neural network for modeling of cutting speed, surface roughness and surface waviness of WEDM process. Amalnik and Farzad [14] reported the use of backpropagation neural network for prediction of EDM process parameters. The networks have four inputs of current $(\mathrm{I})$, voltage $(\mathrm{V})$, period of pulse on (Ton) and period of pulse off (Toff) as the input processes variables. Two outputs results of material removal rate (MRR) and surface roughness (Ra) as performance characteristics. As mentioned above, many researchers studied to find the relationships between input and output parameters in EDM process by using fuzzy logic and neural network.

From the review of literature, it is observed that artificial intelligence techniques including fuzzy logic and neural network have found wide applications in modelling of process parameters and controlling the EDM system components. However, a comprehensive study to compare the performances of fuzzy logic and neural network for modelling of machining quality in EDM is still missing. In this study, discharge current and pulse duration as machining conditions were selected. A fuzzy logic and neural network models were developed and compared using these machining parameters.

The paper gives a short overview of modelling approaches frequently used in manufacturing with emphasis on the workpiece quality. Contribution of this paper is that not only modelling is done by fuzzy logic and neural network, but comparison of two modelling methodologies. Comparative observation showed that the neural network gives slightly smaller deviation of the measured values of model than fuzzy logic model.

\section{DESIGN OF EXPERIMENTS}

Evolutionary Experimental investigation was conducted on an EDM machine tool "FUMEC CNC 21" in South Korea. The work material used in the experiment was manganese-vanadium tool steel, ASTM A681 (0,9\% C, $2 \% \mathrm{Mn}$, and 0,2\% V), hardness $62 \mathrm{HRc}$. The tool was made of electrolytic copper with $99,9 \%$ purity and $20 \times 10 \mathrm{~mm}$ cross-section. The dielectric was petroleum. Due to small eroding surface and depth, natural flushing was used. 
The machining conditions included variable discharge current and pulse duration. The range of the discharge current was $\mathrm{I}_{\mathrm{e}}=1 \div 50$ A (current density $0,5 \div 25 \mathrm{~A} / \mathrm{cm} 2$ ), while the pulse duration was chosen from the interval ti $=1 \div 100 \mu$ s to accommodate the chosen current. The rest of the parameters of electric impulse were held constant, according to the manufacturer's recommendations (open gap voltage $\mathrm{U}_{0}=100 \mathrm{~V}$, duty factor $\tau=0,8$ and positive tool electrode polarity).The experiments were conducted according to the specified experiment plan. Input parameters were varied and the resulting machining parameters of EDM process were monitored and recorded. Measured parameter was surface roughness $\mathrm{R}_{\mathrm{a}}$. Surface integrity was assessed by measuring surface roughness and research of the surface layer properties. "PERTHOMETER S5P" of Mahr, Germany was used to measure the arithmetic average deviation of the assessed profile (ISO 4287) [15].

\section{Modelling Of EdM Process}

\subsection{Fuzzy Logic}

The basic structure of a FIS consists of three conceptual components: a rule base containing a selection of fuzzy rules; a database defining the membership functions (MF) used in the fuzzy rules; and a reasoning mechanism performing the inference procedure upon the rules to derive an output (Figure 1).

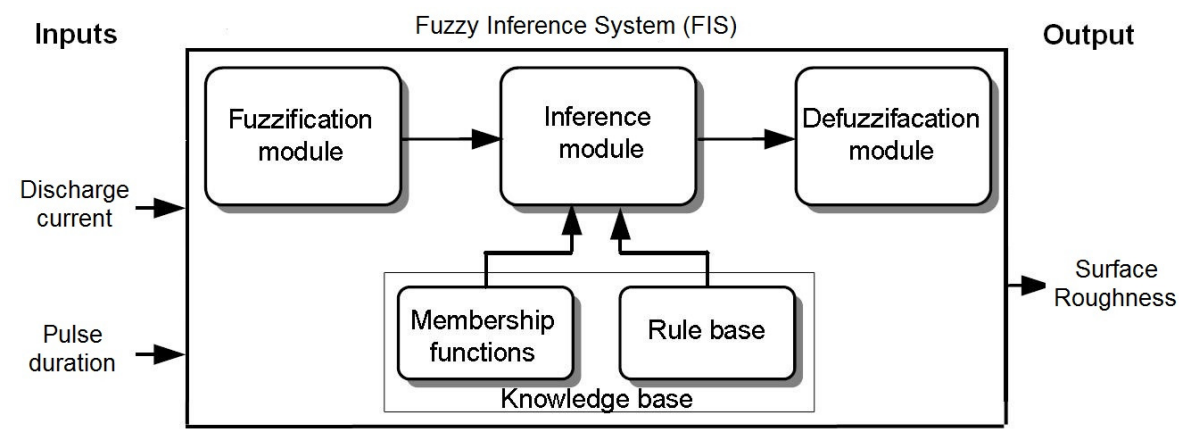

Figure 1. Fuzzy inference system

Design of fuzzy logic system is divided into three phases. The first is to define a fuzzy variable. Then the set of all fuzzy subsets of variables with appropriate membership functions are formed. In the third phase fuzzy rules are formed. For the prediction of output parameter such as surface roughness, the EDM process is modeled using two input parameters such as discharge current and pulse duration. Fuzzy expressions for input variables are as follows: input machining parameters discharge current and pulse duration, have been divided into seven membership functions (Table 1.). 
Table 1. Machining parameters and their levels

\begin{tabular}{c|c|c}
\hline $\begin{array}{c}\text { Levels } \\
\text { (Membership } \\
\text { functions) }\end{array}$ & $\begin{array}{c}\text { Discharge } \\
\text { Current } \\
{[\mathbf{A}]}\end{array}$ & $\begin{array}{c}\text { Pulse } \\
\text { Duration } \\
{[\mu \mathrm{s}]}\end{array}$ \\
\hline Lowest1 & & 1 \\
\hline Lowest & 1 & 2 \\
\hline Lower & 5 & 5 \\
\hline Low & 9 & 7 \\
\hline Medium & 13 & 10 \\
\hline High & 20 & 20 \\
\hline Higher & 30 & 50 \\
\hline Highest & 50 & 100 \\
\hline
\end{tabular}

For example, the functions considered for discharge current are "Lowest",'Lower" "Low" "Medium", "High", "Higher" and "Highest'. Similarly for other parameters, the membership functions have been fixed. The number of membership functions used for the output response is six such as A [1,9-2,3]; B [3,9-5,1]; C [8,8-9,8]; D [10,2-10,8]; E [11,2-12,5]; F [13,2]. More accurate results can be obtained by using more number of membership functions and hence seven membership functions were selected for the present work. The membership function used for the output response surface roughness is presented in Figure 2.

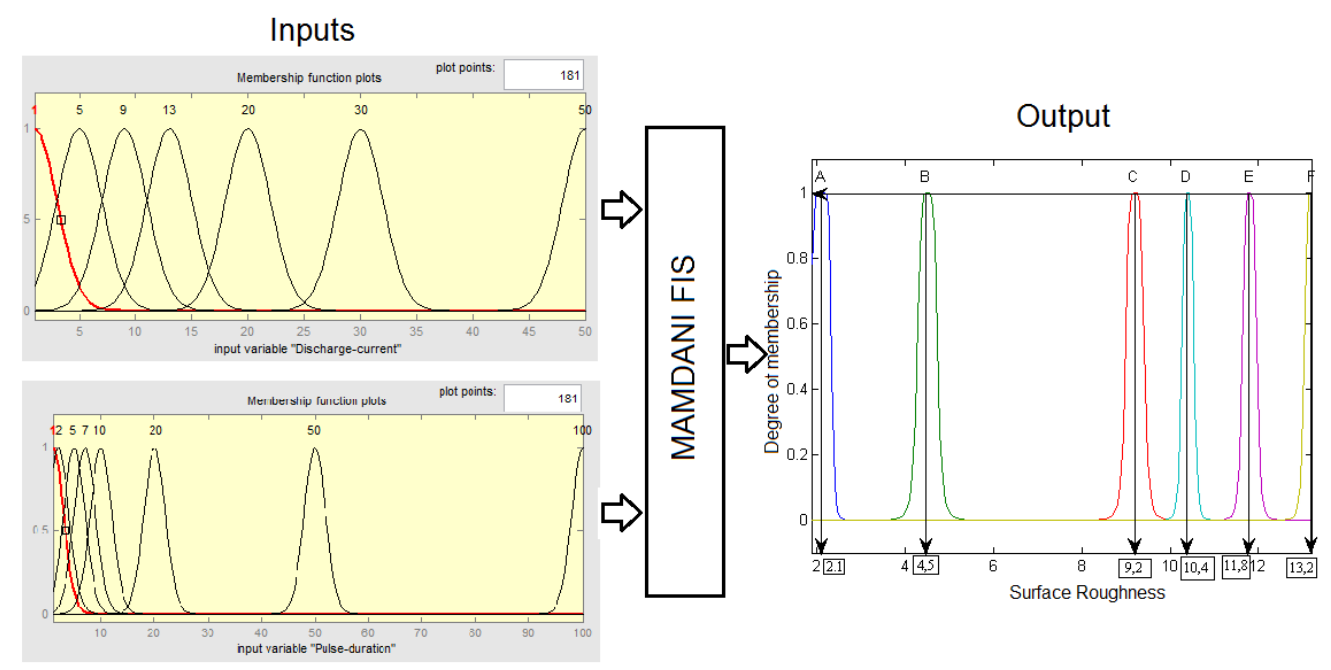

Figure 2. Mamdani FIS with two inputs and one output

In this paper we used the Gaussian type for tool life and cutting temperature modeling. The symmetric Gaussian function depends on two parameters, where $\sigma$ and $\mathrm{c}$ are given:

$$
f(x ; \sigma, c)=e^{\frac{-(x-c)^{2}}{2 \sigma^{2}}}
$$

The fuzzy rule base consists of a group of IF- THEN statements with two inputs: $\mathrm{x}_{1}$ (discharge current) and $\mathrm{x}_{2}$ (pulse duraion) and one output: $\mathrm{y}$ (surface roughness). The rule base of FIS contains fuzzy if-then rules of Mamdani type. In a system with two input and one output, the knowledge base $\mathrm{R}$ contains $\mathrm{n}$ rules in the following form:

$$
R=\left\{R_{1}, R_{2}, \ldots, R_{n}\right\}
$$


where each nth rule has the following form:

$$
\begin{aligned}
& R_{1}: \quad x_{1} \text { is } A_{1} \text { and } x_{2} \text { is } B_{1} \text { THEN } y \text { is } C_{1} \\
& R_{2}: \quad x_{1} \text { is } A_{2} \text { and } x_{2} \text { is } B_{2} \text { THEN } y \text { is } C_{2}
\end{aligned}
$$

where $x$ and $y$ are the inputs of FIS, A and $B$ are the fuzzy sets $f_{i}(x, y)$ is a represents the outputs of the first order Mamdani fuzzy inference system.

Mamdani MIN implication operator is used. Where an implication operators takes as an input membership function of antecedent $\mu_{A i}\left(x_{1}\right) \wedge \mu_{B i}\left(x_{2}\right)$ and $\mu_{C i}(y)$ is consequent. Every rule has a weight (number between 0 and 1) which is applied to the number given by the antecedent. Each rule from the previous set of rules can be viewed as a fuzzy implication, so that the $i^{\text {th }}$ rule can be written as:

$$
\mu_{R i}=\mu_{(A i \wedge B i \Rightarrow C i)}\left(x_{1}, x_{2}, y\right)=\left[\mu_{A i}\left(x_{1}\right) \wedge \mu_{B i}\left(x_{2}\right)\right] \Rightarrow \mu_{C i}(y)
$$

Finally, a defuzzification method is used to transform the fuzzy output into a non-fuzzy value $\mathrm{y}_{0}$. Defuzzification is carried out using centroid defuzzification method. This method is one of the most commonly used defuzzification method that for calculating uses the centroid of the area under the membership function:

$$
y^{\prime}=\frac{\sum_{i=1}^{n} y \mu_{E i}(y)}{\sum_{i=1}^{n} \mu_{E i}(y)}
$$

The non-fuzzy value y' gives the output surface roughness value in numerical form. For example, the value of surface roughness at a condition, discharge current of 5 (A) and pulse duration 2 $(\mu \mathrm{m})$ is obtained as $4,47(\mu \mathrm{m})$.

\subsection{Neural Network}

Modeling of the EDM with feed forward neural network is composed of two stages: training and testing of the network with experimental machining data. The scale of the input and output data is an important matter to consider, especially when the operating ranges of process parameters are different. The scaling or normalization ensures that the NN will be trained effectively without any particular variable skewing the results significantly. As a result, all the input parameters are equally important in the training of network.

The architecture of the designed network comprises two input neurons corresponding to two input parameters, an output layer with one neuron corresponding to one output parameter at a time (Figure 3). Number of neurons is 25, and number of epoch is 100 . The transfer functions which have been used are tansig and purelin in hidden and output layers, respectively. The transfer function tansig is a hyperbolic tangent sigmoid transfer function, and purelin is a linear transfer function. With the help of back propagation training data set (Input parameters related to output parameters) is set to utilize to train the neural network. Two input parameters and one output parameter are considered. The selected input parameters should be easily variable and can be easily changed by the operator. 


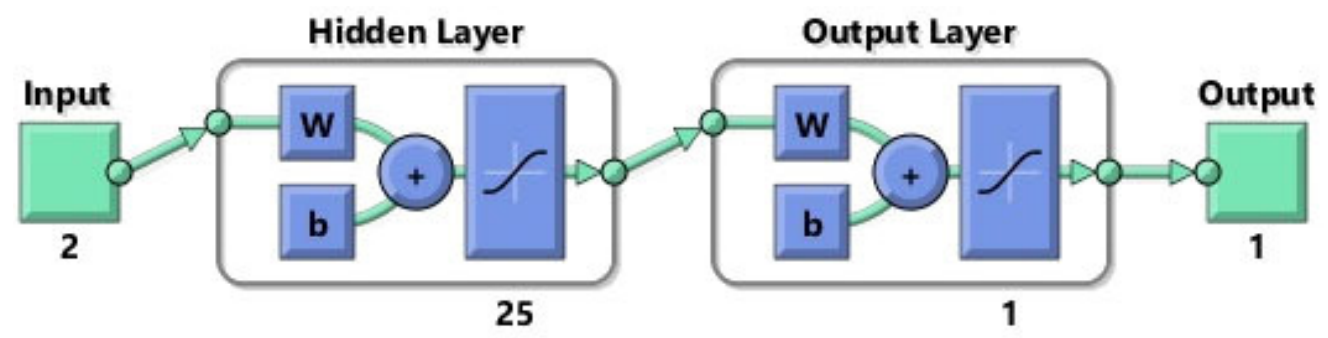

Figure 3. Architecture of the designed network

- Selected input parameters are: discharge current $\mathrm{I}_{\mathrm{e}}(\mathrm{A})$ and pulse duration $\mathrm{t}_{\mathrm{i}}(\mu \mathrm{m})$

- Selected output parameter is: Surface roughness $R_{a}(\mu \mathrm{m})$

A good number of experiments, as shown in Table 1, have been performed, and their results have been used for training and testing of the network. Randomly selected results (70\%) have been used for training, and the rest of the results (30\%) have been used for testing.

\section{RESUltS AND ANALYSIS}

In the EDM machine, the parameter will affect the machining quality on the manganese alloyed cold-work tool steel workpiece is the EDM machine parameter itself. Electrical parameter that may affect the machining quality are pulsed current and pulse time, higher or lower values of these parameters and may decrease or increased the surface integrity.

Table 1 shows the results of experimental investigation for the selected machining conditions. For various discharge currents and pulse durations, with copper electrode, following process parameter is shown: surface roughness. The results of experimental investigation, Table 1 , show a slight increase of surface roughness with the increase of pulse duration, while the discharge current has a more pronounced influence on surface roughness. It is evident that the discharge current defines the surface quality in EDM.

Based on experimental investigation it was established that machining quality of EDM directly depends on the machining conditions. As can be seen, the surface integrity and dimensional accuracy of EDM predominantly depend on the discharge energy but not from properties of the electrode materials. In practice, the discharge energy parameters can be changed by the discharge current and pulse duration.

Fuzzy logic and neural network gives the influence of the discharge current and pulse duration on surface roughness in EDM are investigated through experimental verification. The investigation results confirm the highly consent of experimental research and intelligent techniques modeling. The intelligent optimization techniques and experimental results show some good information which could be used by future researches for optimal control EDM machining conditions. This paper has successfully established fuzzy and neuro models, which consist of the pertinent process parameters, for predicting the surface finish of workpiece.

Figure 4 exhibits the three dimensional surface profile obtained during fuzzy logic modeling for the machining parameters discharge current and pulse duration. In this figure, it can be observed that low discharge current and low pulse duration gives smaller surface roughness. 


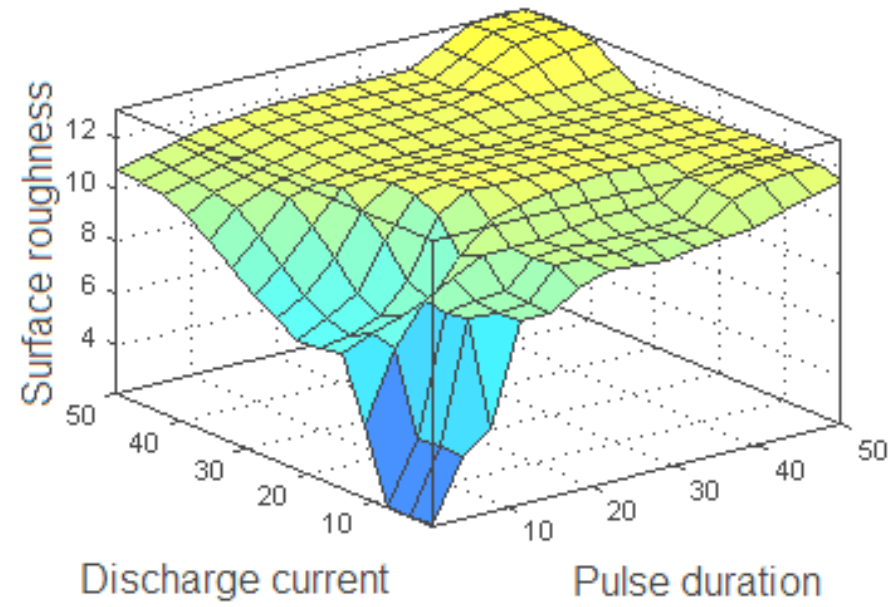

Figure 4. Fuzzy 3D plot of surface roughness

Table 1. The results of experimental investigation

\begin{tabular}{|c|c|c|c|c|c|}
\hline \multirow{4}{*}{$\begin{array}{c}\text { Level } \\
\left(\mathbf{N}^{0}\right)\end{array}$} & \multirow{2}{*}{\multicolumn{2}{|c|}{$\begin{array}{l}\text { Machining } \\
\text { conditions }\end{array}$}} & \multicolumn{3}{|c|}{ Machining characteristics of EDM } \\
\hline & & & \multirow{2}{*}{$\begin{array}{c}\text { Surface } \\
\text { Roughness } \\
\text { (Exp.) }\end{array}$} & \multicolumn{2}{|c|}{ Intelligent techniques } \\
\hline & $\begin{array}{c}\text { Discharge } \\
\text { current }\end{array}$ & $\begin{array}{c}\text { Pulse } \\
\text { duration }\end{array}$ & & Fuzzy logic & $\begin{array}{l}\text { Neural } \\
\text { network }\end{array}$ \\
\hline & $\begin{array}{c}\boldsymbol{I}_{e} \\
(\mathrm{~A})\end{array}$ & $\begin{array}{c}\boldsymbol{t}_{i} \\
(\mu \mathrm{s})\end{array}$ & $\begin{array}{c}\boldsymbol{R}_{a} \\
(\mu \mathrm{m})\end{array}$ & $\begin{array}{c}\boldsymbol{R}_{a F} \\
(\mu \mathrm{m})\end{array}$ & $\begin{array}{c}\boldsymbol{R}_{a N} \\
(\mu \mathrm{m})\end{array}$ \\
\hline 1.1 & \multirow{4}{*}{1} & 1 & 1,8 & 1,81 & 2,02 \\
\hline 1.2 & & 2 & 1,9 & 1,81 & 2,03 \\
\hline 1.3 & & 5 & 2,1 & 1,81 & 2,07 \\
\hline 1.4 & & 7 & 2,3 & 1,81 & 2,11 \\
\hline 2.1 & \multirow{4}{*}{5} & 1 & 3,9 & 4,47 & 3,92 \\
\hline 2.2 & & 2 & 4,2 & 4,47 & 4,06 \\
\hline 2.3 & & 5 & 5,1 & 4,47 & 4,56 \\
\hline 2.4 & & 7 & 5,1 & 4,47 & 4,96 \\
\hline 3.1 & \multirow{4}{*}{9} & 2 & 8,2 & 8,51 & 8,04 \\
\hline 3.2 & & 5 & 8,8 & 8,51 & 8,40 \\
\hline 3.3 & & 7 & 9 & 9,34 & 8,68 \\
\hline 3.4 & & 10 & 9,8 & 9,45 & 9,14 \\
\hline 4.1 & \multirow{4}{*}{13} & 2 & 9,2 & 9,45 & 8,84 \\
\hline 4.2 & & 5 & 9,4 & 9,45 & 9,11 \\
\hline 4.3 & & 7 & 9,7 & 9,48 & 9,35 \\
\hline 4.4 & & 10 & 10,3 & 10,41 & 9,75 \\
\hline 5.1 & \multirow{4}{*}{20} & 5 & 10,2 & 10,41 & 9,90 \\
\hline 5.2 & & 7 & 10,4 & 10,41 & 10,23 \\
\hline 5.3 & & 10 & 10,8 & 10,40 & 10,74 \\
\hline 5.5 & & 20 & 11,2 & 11,40 & 11,95 \\
\hline 6.1 & 30 & 7 & 10,8 & 10,41 & 11,68 \\
\hline
\end{tabular}


International Journal of Recent advances in Mechanical Engineering (IJMECH) Vol.3, No.3, August 2014

\begin{tabular}{|l|l|c|c|c|c|}
\hline 6.2 & & 10 & 11,3 & 11,40 & 11,84 \\
\cline { 3 - 6 } 6.3 & 20 & 11,8 & 11,41 & 12,03 \\
\cline { 3 - 6 } 6.4 & 50 & 12,5 & 12,83 & 12,54 \\
\hline 7.1 & \multirow{4}{*}{7.2} & 10 & 11,8 & 11,41 & 12,30 \\
\hline 7.3 & 20 & 12,5 & 12,83 & 12,64 \\
\hline 7.4 & & 50 & 13,2 & 12,83 & 13,08 \\
\hline & \multicolumn{6}{|c|}{ Average error: } & 13,36 & 13,39 \\
\cline { 2 - 5 } & 100 & 13,4 & $\mathbf{4 , 8 0 \%}$ & $\mathbf{4 , 0 1 \%}$ \\
\hline
\end{tabular}

\section{CONCLUSION}

In this paper a fuzzy logic and neural network are used to estimate surface roughness in EDM. The average error of models are checked and is found to be adequate for fuzzy model is $4,8 \%$ and neural network is 4,01 confidence level and the all models can be used for predicting the surface roughness in EDM. Figure 5 depict the comparisons of experimental, fuzzy and neuro results for the surface roughness, respectively. The comprised lines seem to be close to each other indicating with good agreement.

All models show good agreement with experimental results. When compared to the NN and FL models, the NN model has shown a significant forecast improvement. The results indicate that the $\mathrm{NN}$ model is an effective algorithm to forecast the surface roughness in EDM. The effectiveness of the models is only within the range and factors studies. The model adequacy can be further improved by considering more variables and ranges of parameters.

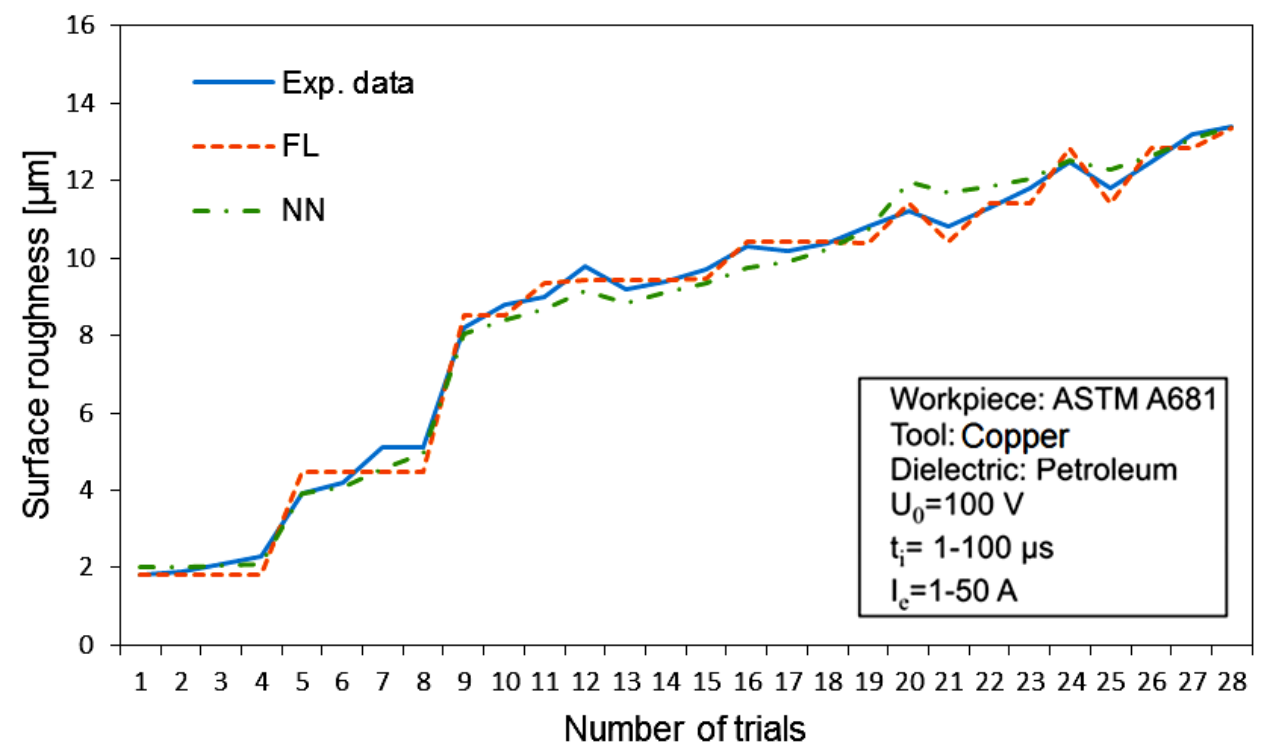

Figure 5. Correlation between experimental, FL and NN surface roughness value

\section{ACKNOWLEDGEMENTS}

The paper is the result of the research within the project TR 35015 financed by the ministry of science and technological development of the republic of Serbia. 


\section{REFERENCES}

[1] Chen, J. C., Savage, M. (2001) "A fuzzy-net-based multilevel in process surface roughness recognition system in milling operations" The International Journal of Advanced Manufacturing Technology, Vol. 17, pp. 670-676.

[2] Kovac, P., Rodic, D., Pucovsky, V., Savkovic, B., Gostimirovic, M. (2013). "Application of fuzzy logic and regression analysis for modeling surface roughness in face milling". Journal of Intelligent Manufacturing, Vol. 24, pp.755-762.

[3] Gostimirovic, M., Kovac, P., Skoric, B., Sekulic, M. (2011) "Effect of electrical pulse parameters on the machining performance in EDM". Indian Journal of Engineering and Material Sciences, Vol. 18, pp. 411-415.

[4] Caydas, U., Hascalık a, A., Ekici, S. (2009) "An adaptive neuro-fuzzy inference system (ANFIS) model for wire-EDM” Expert Systems with Applications, Vol. 36, pp. 6135-6139.

[5] Radovanovic, M., Madic, M. (2010) "Methodology of neural network based modeling of machining processes" International Journal of Modern Manufacturing Technologies, Vol. 2, pp. 77-82.

[6] K. Wang, H.L. Gelgele, Y. Wang, Q. Yuan, M. Fang. (2003) “A hybrid intelligent method for modelling the EDM process" International Journal of Machine Tools and Manufacture, Vol. 43, pp. 995-999.

[7] Panda, D.K.; Bhoi, R.K. (2005) "Artificial neural network prediction of material removal rate in electro discharge machining" Materials and Manufacturing Processes, Vol.20, pp. 645-672.

[8] Yilmaz, O., Eyercioglu, O., Gindy, N.Z. (2006) “A user-friendly fuzzy based system for the selection of electro discharge machining process parameters" Journal of Materials Processing Technology, Vol. 172, pp. 363-371.

[9] Rao, P.S., Prasad, K.E., Reddy, B.S. (2011) "Fuzzy modelling for electrical discharge machining of aluminium alloy" International Journal of Research and Reviews in Applied Sciences, Vol. 9, pp. 112 125.

[10] Lin JL, Wang KS, Yan BH, Tarng YS. (2000) "Optimization of the electrical discharge machining process based on the Taguchi method with fuzzy logics" Journal of Materials Processing Technology, Vol. 102, pp. 48-55.

[11] Shabgarda, M.R., Badamchizadehb, M.A., Ranjbarya, G., Aminic, K. (2012) "Fuzzy approach to select machining parameters in electrical discharge machining (EDM) and ultrasonic-assisted EDM processes" Journal of Manufacturing Systems, Vol. 32, PP. 32-39.

[12] Tsai KM, Wang PJ (2001) "Predictions on surface finish in electrical discharge machining based upon neural network models" International Journal of Machine Tools and Manufacture, Vol. 10, pp. 13851403.

[13] Spedding TA, Wang ZQ (1997) "Study on modeling of wire EDM process" J Mater Process Technol, Vol. 69, pp. 18-28.

[14] Amalnik MS, Farzad M (2005) "Neural network radial based function (RBF) approach in predicting of material removal rate and surface roughness in electrical discharge machining" In: Proceedings of systems of designing, technological preparation of manufacture and management of stages of life cycle of industrial product CAD/CAM/PDM-2005, http://lab18.ipu.rssi.ru/projects/conf2005/Accessed 19th July 2007.

[15] Gostimirovic, M., Kovac, P., Sekulic, M., Skoric, B., (2012). "Influence of discharge energy on machining characteristics in EDM". Journal of Mechanical Science and Technology, Vol. 26, pp.173179. 


\section{Authors}

MSc Dragan Rodic is a PhD student on the University of Novi Sad, Faculty of Technical Sciences in Serbia. He is currently research assistant at the Department of Production Engineering (2011). His research interests include advanced manufacturing - cutting techniques, process modeling and artificial intelligence.

Prof. dr Marin Gostimirovic received his B.S, M.S. and Ph.D. degrees from the University of Novi Sad, Serbia, in 1982, 1989 and 1997, respectively. He is currently a full professor at the Faculty of Technical Science at University of Novi Sad, Serbia. His research interests include advanced manufacturing - cutting techniques, non-conventional processes, heat phenomena, process modeling and artificial intelligence.

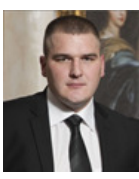

Prof. dr Pavel Kovac received his B.S, M.S. and Ph.D. degrees from the University of Novi Sad, Serbia, in 1975, 1980 and 1987, respectively. He is currently a full professor at the Faculty of Technical Science at University of Novi Sad, Serbia. His research interests include machining technology, metal cutting and high productive technologies, ecological systems and technologies, plastics and environment, design of experiment and artificial intelligence.

Prof. dr Miroslav Radovanovic: Dr Miroslav Radovanovic, Professor at Faculty of Mechanical Engineering in Nis, University of Nis, Serbia, has had got 30 years of experience in application of production technologies in mechanical engineering and in education. His research interests include advanced manufacturing - cutting techniques, non-conventional processes, heat phenomena, process modeling and artificial intelligence.

MSc Borislav savkovic is a $\mathrm{PhD}$ student on the University of Novi Sad, Faculty of Technical Sciences in Serbia. He is currently teaching assistant at the Department of Production Engineering (2008). His research interests include advanced manufacturing cutting techniques, process modeling and artificial intelligence.
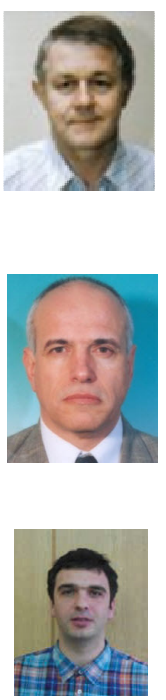